\title{
COMUNICAÇÃO
}

\section{MODIFICAÇÕES NAS ATIVIDADES DA POLIGALACTURONASE E PECTINAMETILESTERASE EM MORANGOS ARMAZENADOS A TEMPERATURA AMBIENTE}

\author{
Modifications in the activities of poligalacturonase and pectinametilesterase in stored \\ strawberries the ambient temperature
}

\author{
Polyanna Alves Silva1, Celeste Maria Patto de Abreu², Angelita Duarte Corrêa ${ }^{3}$, Simone Abreu Asmar $^{4}$
}

\begin{abstract}
RESUMO
Objetivou-se, neste trabalho, avaliar as modificações da poligalacturonase (PG) e da pectinametilesterase (PME) em morangos cultivados na região de Lavras, MG, e armazenados em temperatura ambiente. Foram utilizados morangos das cultivares 'Osogrande', 'Toyorrinho' e 'Tudla'. Utilizou-se o delineamento inteiramente casualizado com 4 repetições, sendo os tratamentos arranjados em esquema fatorial (3X2), sendo 3 cultivares e 2 dias de análises ( 0 e 5 dias). A parcela experimental foi constituída por 10 frutos. Durante o armazenamento houve uma diminuição nos teores de pectina total e um aumento nos de pectina solúvel em todas as variedades analisadas. A atividade da PG e PME aumentaram com o período de armazenamento, independente da cultivar.
\end{abstract}

Termos para indexação: Poligalacturonase, pectinametilesterase, morangos, Fragaria ananassa.

\begin{abstract}
The objective of this research was to evaluate the modifications of the polygalacturonase (PG) and the pectinmethilesterase (PME) in strawberries cultivated in the region of Lavras, MG, and stored at room temperature. Strawberries of the research were used for plantation of 'Oso-grande', 'Toyorrinho' and 'Tudla'. The entirely randomized design with 4 replicates was used, being the treatments arranged in factorial ( $3 \times 2)$, being 3 plantations and 2 days of analyses ( 0 and 5 days). The experimental parcel was consisted by 10 fruits. During the storage there was a reduction in the levels of total pectin and an increase in the ones of soluble pectin in all the analyzed varieties. With the period of storage the PG and PME activity grew, independent of the cultivar.
\end{abstract}

Index terms: Poligalacturonase, pectinametilesterase, strawberries, Fragaria ananassa.

(Recebido em 28 de março de 2007 e aprovado em 15 de setembro de 2008)

Alterações na aparência e perda de firmeza, mudanças que mais ocorrem em frutos durante o armazenamento. A firmeza é a propriedade do alimento perceptível pelo tato e está relacionada à intensidade de sua deformação ou desintegração, sob a aplicação de uma força (CHITARRA, 1999).

Os frutos ao serem colhidos, normalmente apresentam um material ceroso protetor sobre a casca ou epiderme. Essa camada protege as células internas do amaciamento ocasionado por danos mecânicos, físicos dentre outros.

A transformação mais evidente que ocorre durante a maturação é a mudança da cor e o amolecimento do fruto.
A firmeza afeta a qualidade do fruto e tem importância econômica pelo seu efeito na resistência ao transporte, na conservação e no ataque de microrganismos (OLIVEIRA, 2005).

As pectinas são importantes, não só como fatores primários no processo de amolecimento, mas também devido à possível contribuição no metabolismo da célula (THÉ et al., 2001).

Um grande número de enzimas tem participação na degradação biológica das substâncias pécticas. Dentre elas, as mais importantes e objetos de maiores estudos, estão as pectinametilesterases (PME) e as poligalacturonases (PG). É de grande importância o

1'Doutoranda em Química - Departamento de Química/DQI - Universidade Federal de Lavras/UFLA - Cx. P. 3037 - $37200-000$ - Lavras, MG polyanna@ufla.br

Engenheira Agrônoma, Doutora, Professora Associada II - Departamento de Química/DQI - Universidade Federal de Lavras/UFLA - Cx. P. 3037 37200-000 - Lavras, MG - celeste@ufla.br

${ }^{3}$ Engenheira Agrônoma, Doutora, Professora Associada II - Departamento de Química/DQI - Universidade Federal de Lavras/UFLA - Cx. P. 3037 37200-000 - Lavras, MG - angelita@ufla.br

${ }^{4}$ Engenheira Agrônoma, Doutoranda - Departamento de Agricultura/DAG - Universidade Federal de Lavras/UFLA - Cx. P. 3037 - $37200-000$ - Lavras, MG siasmar@yahoo.com.br 
conhecimento da fisiologia pós-colheita de um fruto para que se tenha subsídio técnico que vise à ampliação do tempo de armazenamento, sem alteração da qualidade. Objetivou-se, neste trabalho, acompanhar as modificações nas atividades da PG e PME ocorridas durante o armazenamento de morangos cultivados na região de Lavras, MG, em temperatura ambiente.

Foram utilizados morangos das cultivares Osogrande, Toyorrinho e Tudla provenientes de um pomar comercial da região de Itutinga, Minas Gerais, situado a $910 \mathrm{~m}$ de altitude, e nas coordenadas geográficas de $21^{\circ} 18^{\prime} 45^{\prime \prime}$ de latitude Sul e 4441'15" de longitude W. Gr. (IBGE, 1959). Foram colhidos 300 frutos que foram levados para o Laboratório de Bioquímica do Departamento de Química da UFLA, em Lavras, MG, onde foram selecionados 80 de cada cultivar, em relação ao tamanho, estágio de maturação e ausência de desordens fisiológicas ou doenças.

Utilizou-se o delineamento inteiramente casualizado (DIC), sendo os tratamentos arranjados em esquema fatorial (3X2), sendo 3 cultivares e 2 dias de análises, correspondentes aos dias 0 e 5 , com 4 repetições de 10 frutos para cada tratamento.

Após selecionar 80 frutos de cada cultivar, eles foram divididos em 2 grupos, que foram:

- $1^{\circ}$ grupo: 40 frutos de cada cultivar, para as análises do dia da colheita;

- $2^{\circ}$ grupo: 40 frutos de cada cultivar foram armazenados em uma bancada do Laboratório de Bioquímica da UFLA, à temperatura ambiente $\left(17^{\circ} \mathrm{C} \mathrm{e}\right.$ $69 \%$ UR), por cinco dias.

Os resultados foram submetidos à análise de variância, por meio do programa estatístico Sanest para Windows e, quando significativas, as médias foram comparadas, pelo teste de Tukey, a 5\% de probabilidade (ZONTA \& MACHADO, 1991).

\section{Análises químicas:}

\section{Pectina total e solúvel}

A extração das substâncias pécticas foi realizada segundo a técnica descrita por McCready \& McComb (1952). A determinação colorimétrica foi feita por meio da reação com carbazol, segundo a técnica de Bitter \& Muir (1962). Os resultados foram expressos em mg de ácido galacturônico por $100 \mathrm{~g}$ de polpa.

\section{Porcentagem de solubilização}

O cálculo da porcentagem de solubilização foi feito a partir dos dados de pectina total e solúvel, por meio da seguinte equação: \% de solubilização = (pectina solúvel/ pectina total) X 100.

\section{Análises de atividades enzimáticas:}

\section{Atividade da pectinametilesterase (PME)}

A PME foi determinada segundo Jen \& Robinson (1984). Uma unidade de PME foi definida como a quantidade de enzima capaz de catalisar a desmetilação de pectina correspondente ao consumo de $1 \mathrm{nmol}$ de $\mathrm{NaOH}$ por minuto, por grama de tecido, sob as condições do ensaio.

\section{Atividade de poligalacturonase (PG)}

A atividade enzimática da $\mathrm{PG}$ foi determinada segundo Markovic et al. (1975), e consiste na hidrólise de substâncias pécticas e, conseqüentemente, na liberação de grupos redutores. Esses foram doseados pela técnica de Somogyi, adaptada por Nelson (1944). Uma unidade de atividade de PG foi definida como a quantidade de enzima capaz de catalisar formação de $1 \mathrm{nmol}$ de açúcar redutor por minuto por grama de tecido, sob as condições de ensaio.

\section{Pectina total, solúvel e porcentagem de solubilização}

Houve efeito significativo para a interação entre os fatores cultivar $\mathrm{x}$ dias de armazenamento para a variável pectina total $(\mathrm{p}<0,01)$. Durante o período de armazenamento, houve uma diminuição nos teores de pectina total, em todas as cultivares analisadas (Tabela 1). A 'Oso-Grande' apresentou maior teor de pectina total, comparada com as outras cultivares estudadas.

As porcentagens de redução de pectina total foram de $10 \%, 31 \%$ e $21 \%$, nas cultivares Oso-Grande, Tudlla e Toyorrinho, respectivamente.

No decorrer do amadurecimento, há transformação da protopectina em pectina total e essa, por ação enzimática, sofre desmetilação e simplificação das cadeias, causando a solubilização até a degradação total, quando a fruta está muito madura (Fonseca, 1974; Nunes, 2004).

A variável pectina solúvel foi afetada significativamente somente pelo fator tempo de armazenamento ( $p<0,01)$, não se observando efeito isolado do fator cultivar e nem interação significativa entre esses dois fatores.

Houve um aumento nos teores de pectina solúvel ao longo do armazenamento (Tabela 2). Esse aumento se deve ao aumento das atividades das enzimas PME (Tabela 4) e PG (Tabela 5). 
Gross \& Wallner (1979) relataram que, na maioria dos frutos, a fração solúvel das substâncias pécticas aumenta durante o amadurecimento, num processo atribuído à ação de enzimas pectolíticas.

O processo de solubilização das substâncias pécticas contribui para o amaciamento dos tecidos das frutas em decorrência da redução da força de coesão entre as células (CHITARRA, 1999).

A interação entre os fatores cultivar e dias de armazenamento foi significativa para a variável \% de solubilização $(\mathrm{p}<0,01)$.

Ocorreu um aumento da porcentagem de solubilização das pectinas durante o armazenamento, em todas as cultivares de morangos analisadas, tendo a cultivar Toyorrinho uma maior solubilização que a 'Tudlla' e a 'Oso-Grande' (Tabela 3). A ‘Toyorrinho' apresentou maior atividade PME (Tabela 4).

A solubilização de substâncias pécticas é uma tendência natural durante o amadurecimento dos frutos (OLIVEIRA, 2005).

Amour \& Asboe-Hansen (1993) observaram grande solubilização de pectinas e relataram que essa solubilização contribui para o amadurecimento de morangos.

Camargo et al. (2000), em estudo com morangos cv. Campineiro, também observaram uma tendência de elevação da \% de solubilização nos frutos-testemunha.

Tabela 1 - Teores médios de pectina total (mg ácido galacturônico/100 mg polpa) em três cultivares de morangos armazenados a temperatura ambiente, por um período de cinco dias, sob condições ambientais.

\begin{tabular}{cccc}
\hline Cultivar & Oso-Grande & Tudlla & Toyorrinho \\
Dias & $0,55 \mathrm{a} \mathrm{A}$ & $0,54 \mathrm{~b} \mathrm{~A}$ & $0,52 \mathrm{c} \mathrm{A}$ \\
0 & $0,49 \mathrm{a} \mathrm{B}$ & $0,37 \mathrm{c} \mathrm{B}$ & $0,41 \mathrm{~b} \mathrm{~B}$ \\
5 & $0,52 \mathrm{a}$ & $0,45 \mathrm{c}$ & $0,47 \mathrm{~b}$ \\
\hline
\end{tabular}

Médias seguidas por letras distintas minúsculas nas linhas e maiúsculas nas colunas diferem entre si, pelo teste de Tukey, a 5\% de probabilidade.

Tabela 2 - Teores médios de pectina solúvel (mg ácido galacturônico/100 mg polpa) em três cultivares de morangos armazenados por cinco dias, sob condições ambientais.

\begin{tabular}{cc}
\hline Dias & Médias \\
\hline 0 & $0,35 \mathrm{~B}$ \\
5 & $0,45 \mathrm{~A}$ \\
\hline
\end{tabular}

Médias seguidas por letras distintas diferem entre si, pelo teste de Tukey, a 5\% de probabilidade.

Tabela 3 - \% de Solubilização de três cultivares de morangos armazenados à temperatura ambiente, por um período de cinco dias, sob condições ambientais.

\begin{tabular}{cccc}
\hline Cultivar & Oso-Grande & Tudlla & Toyorrinho \\
\hline & & & $64,24 \mathrm{a} \mathrm{B}$ \\
5 & $66,37 \mathrm{a} \mathrm{B}$ & $60,67 \mathrm{a} \mathrm{B}$ & $118,33 \mathrm{a} \mathrm{A}$ \\
& $96,32 \mathrm{~b} \mathrm{~A}$ & $114,00 \mathrm{a} \mathrm{A}$ & $91,29 \mathrm{a}$ \\
\hline
\end{tabular}

Médias seguidas por letras distintas minúsculas nas linhas e maiúsculas nas colunas diferem entre si, pelo teste de Tukey, a 5\% de probabilidade. 
Tabela 4 - Atividade de pectinametilesterase (PME) (nmol/min/g polpa), em três cultivares de morangos armazenados à temperatura ambiente, por um período de cinco dias, sob condições ambientais.

\begin{tabular}{|c|c|c|c|}
\hline Dias Cultivar & Oso-grande & Tudlla & Toyorrinho \\
\hline 0 & 19,64 a B & $10,84 \mathrm{~b} \mathrm{~A}$ & 22,58 a B \\
\hline 5 & $25,89 \mathrm{~b} \mathrm{~A}$ & $13,32 \mathrm{c} \mathrm{A}$ & 34,09 a A \\
\hline Média & $22,77 \mathrm{~b}$ & $12,08 \mathrm{c}$ & $28,33 \mathrm{a}$ \\
\hline
\end{tabular}

Médias seguidas por letras distintas minúsculas nas linhas e maiúsculas nas colunas diferem entre si, pelo teste de Tukey, a 5\% de probabilidade.

Tabela 5 - Atividade de poligalacturonase $(\mathrm{PG})(\mathrm{nmol} / \mathrm{min} / \mathrm{g}$ polpa), em três cultivares de morangos armazenados à temperatura ambiente, por um período de cinco dias, sob condições ambientais.

\begin{tabular}{cccc}
\hline Cultivar & Oso-Grande & Tudlla & Toyorrinho \\
\hline 0 & $0 \mathrm{a} \mathrm{B}$ & $0 \mathrm{a} \mathrm{B}$ & $0 \mathrm{a} \mathrm{B}$ \\
5 & $833,11 \mathrm{~b} \mathrm{~A}$ & $888,50 \mathrm{a} \mathrm{A}$ & $712,50 \mathrm{c} \mathrm{A}$ \\
Média & $417,05 \mathrm{~b}$ & $444,75 \mathrm{a}$ & $356,75 \mathrm{c}$ \\
\hline
\end{tabular}

Médias seguidas por letras distintas minúsculas nas linhas e maiúsculas nas colunas diferem entre si, pelo teste de Tukey, a $5 \%$ de probabilidade.

\section{Atividade enzimática da poligalacturonase (PG) e da pectinametilesterase (PME)}

Houve diferenças significativas entre os fatores cultivar e dias de armazenamento, observando interação entre esses dois fatores para as atividades enzimáticas da poligalacturonase (PG) e da pectinametilesterase (PME) $(\mathrm{p}<0,01)$.

A atividade da PME aumentou com o período de armazenamento, para as três cultivares (Tabela 4), tendo ‘Toyorrinho' apresentado a maior atividade enzimática e a 'Tudlla', a menor atividade. Já a atividade da PG também aumentou durante o armazenamento para todas as variedades, tendo a 'Tudlla' apresentado maior atividade que as demais cultivares (Tabela 5).

$\mathrm{Na}$ literatura, foram encontrados relatos de que, na maioria dos frutos, a atividade da PG aumenta durante o amadurecimento concomitantemente com um aumento na maciez do fruto (BICALHO et al., 2000; HOBSON \& GRIERSON, 1993; HUBER, 1984; KNEE \& BARTHEY, 1981). Os autores também relataram que, normalmente, a degradação de polissacarídeos da parede celular é acompanhada por um aumento na atividade de poligalacturonase (enzimas responsáveis pela solubilização de pectinas) e pectinametilesterase (enzimas que catalizam a desesterificação de grupos carboxílicos livres) (GONÇALVES, 1998).
Provavelmente, o aumento da solubilização das substâncias pécticas foi devido à atividade remanescente da enzima poligalacturonase (PG), que foi suficiente para promover o amolecimento dos morangos, durante o armazenamento.

Observou-se, neste experimento, que a cv. Toyorrinho apresentou maior atividade de PME (Tabela 4) e menor atividade de PG (Tabela 5). Isso está de acordo com Seymour et al. (1987) que relatam que altos níveis de atividade de PME inibem a hidrólise, indicando que a PG deve agir sobre um substrato com uma extensão limitada de desesterificação.

Camargo et al. (2000), estudando o efeito do cálcio sobre o amadurecimento de morangos cv. Campineiro, também observaram que a atividade da poligalacturonase (PG) e da pectinametilesterase (PME) aumentaram nos frutos-controle, durante o amadurecimento. Constataram também que, tanto a atividade da PG quanto a solubilização de pectinas, aumentaram durante o amadurecimento.

Nas condições em que o experimento foi realizado, pôde-se concluir que:

- os frutos da cv. Oso-Grande apresentaram maiores valores de pectina total e menores atividades das pectinametilesterases e \% de solubilização;

- os frutos da cv. Tudlla apresentaram maiores atividades das poligalacturonases e menores valores de pectina total; 
- os frutos da cv. Toyorrinho apresentaram maiores valores de \% de solubilização e atividades das pectinametilesterases e menores atividades das poligalacturonases.

\section{REFERÊNCIAS BIBLIOGRÁFICAS}

AMOUR, J. d'; ASBOE-HANSEN, G. New method for quantitative determination of uronic acids. Analytical Biochemistry, New York, v. 54, n. 3, p. 484-489, Apr. 1973.

BICALHO, U. de; CHITARRA, A. B.; CHITARRA, M. I. F.; COELHO, A. H. R. Modificações texturais em mamões submetidos à aplicação pós-colheita de cálcio e embalagens de PVC. Ciência e Agrotecnologia, Lavras, v. 24, n. 1, p. 136-146, jan./mar. 2000.

BITTER, T.; MUIR, H. M. A modified uronic acid carbazole reaction. Analytical Biochemistry, New York, v. 34, n. 4, p. 330-334, 1962.

CAMARGO, Y. R.; LIMA, L. C. de O.; SCALON, S. de P. Q.; SIQUEIRA, A. C. Efeito do cálcio sobre o amadurecimento de morangos (Fragaria ananassa Duch) cv. Campineiro. Ciência e Agrotecnologia, Lavras, v. 24, n. 4, p. 968-972, out./dez. 2000.

CHITARRA, A. B. Armazenamento de frutos e hortaliças por refrigeração. Lavras: UFLA/FAEPE, 1999. $58 \mathrm{p}$.

FONSECA, H. Amadurecimento de frutas. In: FONSECA, H. et al. Bioquímica de alimentos. Piracicaba: ESALQ, 1974. 249 p.

GONÇALVES, N. B. Efeito da aplicação de cloreto de cálcio associado ao tratamento hidrotérmico sobre a composição química e suscetibilidade ao escurecimento interno do abacaxi, cv. Smoth Cayenne. 1998. 101 p. Tese (Doutorado em Fitotecnia) - Universidade Federal de Lavras, Lavras, 1998.

GROSS, K. C.; WALLNER, S. J. Degradation of cell wall polyssaccharides during tomato druit ripening. Plant Physiology, Baltimore, v. 63, n. 1, p. 117-120, July 1979.

HOBSON, G. E.; GRIERSON, D. Tomato. In: SEYMOUR, G. B.; TAYLOR, J. E.; TUCKER, G. A. Biochemistry of fruits ripening. London: Chapman \& Hall, 1993. cap. 13, p. $405-442$.
HUBER, D. J. Strawberry fruit soffening: the potential roles of polyuronides and hemiceluloses. Journal of Food Science, Chicago, v. 49, n. 5, p. 1310-1315, Sep./Oct. 1984.

\section{INSTITUTO BRASILEIRO DE GEOGRAFIA E} ESTATÍTICA. Enciclopédia dos municípios brasileiros. Rio de Janeiro, RJ, 1959. 670 p.

JEN, J. J.; ROBINSON, M. L. P. Pectolytic enzymes in sweet bell peppers (Capsicum annum L.). Journal of Food Science, Chicago, v. 49, n. 4, p. 1085-1087, July/ Aug. 1984.

KNEE, M.; BARTLEY, I. M. Composition and metabolism of cell wall polyssaccharides in ripening fruits. In: FRIEND, J.; RHODES, M. J. C. (Eds.). Recent advance in the biochemistry of fruits and vegetables. London: Academic, 1981. cap. 7, p. 131-146.

MARKOVIC, O.; HEINRICHOVÁ, K.; LENKEY, B. Pectolytic enzymes from banana. Collection Czechoslovak Chemistry Community, London, v. 40, n. 3, p. 769-774, 1975.

McCREADY, P. M.; McCOMB, E. A. Extraction and determination of total pectic material. Analytical Chemistry, Washington, v. 24, n. 12, p. 1586-1588, Dec. 1952.

NELSON, N. A. A photometric adaptation of Somogy method for the determination of glucose. The Journal of Biological Chemistry, Baltimore, v. 135, n. 1, p. 136-175, May 1944.

NUNES, E. E. Conservação de mandioquinha: salsa minimamente processada. Lavras: UFLA, 2004. 18 p.

OLIVEIRA, F. E. da R. Qualidade de pêssegos 'Diamante' (Prunus pérsica (L.) Batsch) submetidos ao 1metilciclopropeno. 2005. 68 p. Dissertação (Mestrado em Agroquímica e Agrobioquímica) - Universidade Federal de Lavras, Lavras, 2005.

SEYMOUR, G. B.; LASSLET, Y.; TUCKER, G. A. Differential effects pectolytic enzymes on tomato polyuronides in vivo and in vitro. Phytochemistry, Oxford, v. 26, n. 12, p. 3137-3139, Dec. 1987. 
HÉ, P. M.; CARVALHO, V. D. de; ABREU, C. M. P. de; NUNES, R. de P.; PINTO, N. A. V. D.

Modificações na atividade enzimática em abacaxi 'Smooth Cayenne' em função da temperatura de armazenamento e do tecido de maturação. Ciência e
Agrotecnologia, Lavras, v. 25, n. 2, p. 364-370, mar./ abr. 2001.

ZONTA, E. P.; MACHADO, A. A. Manual do SANEST: sistema de análise estatística para microcomputadores. Pelotas: UFP, 1991. 102 p. 